\title{
Teen Laborer Rides on Side of Forklift, Falls While Jumping, and is Run Over by Rear Tire
}

\section{CASE SUMMARY}

At approximately 4:50 pm on Tuesday, November 4, 2015, a 17-year-old teen laborer (the victim) and another 19-year-old laborer were at the end of their 8hour work day at an agricultural distribution center and were storing a rough terrain JCB 930 forklift in a gated parking lot for the day. The 19 year-old laborer was operating the forklift when he offered the victim a ride to the storage area. The victim climbed onto the side step of the forklift, which was not designed to accommodate passengers, and held on to the forklift frame. As they neared the gated lot, the victim volunteered to open the gate. Jumping from the

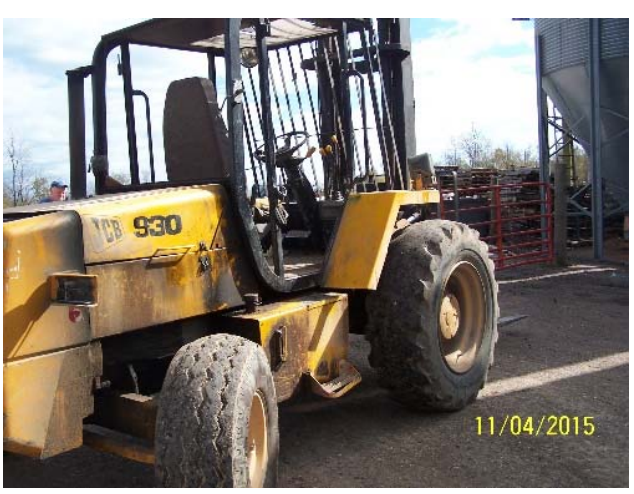

Figure 1. Rough Terrain JCB 930 forklift. forklift while it was moving, the victim's foot caught in the forklift's back wheel guard, and he fell face first to the dirt lot. Unaware that the victim had fallen, the second laborer continued driving the forklift forward until he realized the back left tire had tread onto the victim. The second laborer immediately rolled the forklift back off of the victim. A customer, who was also a physician, heard the forklift driver's screams for help and ran to offer assistance. The physician ordered the employees not to move the victim while a third laborer at the distribution center immediately contacted 911. Emergency medical services arrived at the scene within 15 minutes and called air transport. The victim was air transported and arrived at a major trauma center at 6:15 pm. He died from his injuries at 6:52 pm.

\section{Recommendations for prevention:}

- Do not allow passenger(s) to ride on a forklift unless the forklift is specifically designed to accommodate passengers.

- Employers should provide and enforce forklift operator safety training.

- Employers should review regulations pertaining to safe operation of forklifts and other equipment prior to allowing their use on the jobsite. 


\section{EMPLOYER}

The employer is a small family owned farm equipment and supply wholesaler that supplies a variety of agricultural products, including livestock health products, bulk feed, insecticides, equipment, and more. The company has been in business since 1986 and at the time of the incident employed 5 full-time and 2 part-time employees.

\section{SAFETY AND TRAINING PROGRAMS}

The employer had no written safety programs, and was unaware of federal OSHA regulations prohibiting passengers from riding a forklift unless a passenger seat is available. ${ }^{1}$ Employees interviewed at the scene stated that workers routinely rode as passengers on single-seat forklifts from building to building due to the distance. On-the-job training was the only training provided.

\section{VICTIM}

The victim was a 17-year-old high school student who was completing his second day on the job. He had been hired as a laborer to work from 3:30-5:30 pm after school and for 4 hours on Saturdays. According to his coworkers he was excited to be away from school for Election Day and able to work a full 8-hour day, thus allowing other employees time off to vote.

\section{INCIDENT SCENE}

The storage area was positioned uphill behind the main store. A weathered, paved entrance led into a gated area where equipment and supplies were routinely stored. Assessment of the area surrounding the incident scene did not reveal any significant drops or potholes. The distance that the two laborers travelled on the forklift between the main store and the storage area measured approximately 245 feet.

Figure 2. A) Area where the forklift was to be stored. B) Area of the ground where the victim was struck by the forklift. C) Aerial view showing the distance the two laborers travelled on the forklift between the main store and the storage area.

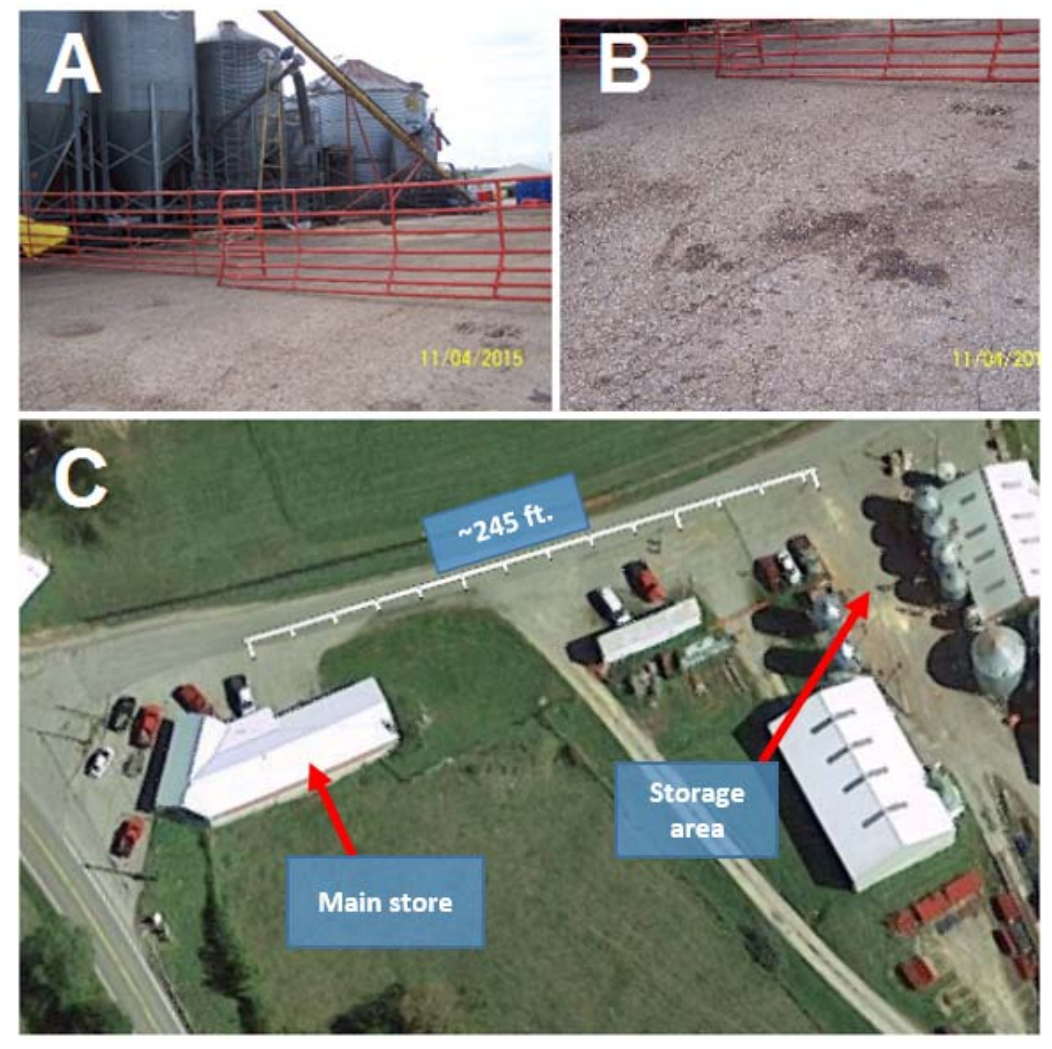




\section{EQUIPMENT}

The equipment used at the job site was a JCB930 rough terrain forklift. This forklift is designed with a lift capacity of 6,000 to 10,000 pounds and a lift height of 15-22 feet. The lift was used to load and unload equipment purchased by customers and delivered by suppliers, and was equipped with one seat for a single operator. The forklift was not loaded at the time of the incident. A review of the user manual revealed that the JCB 930 was not designed to allow passengers, and that doing so could cause injury.

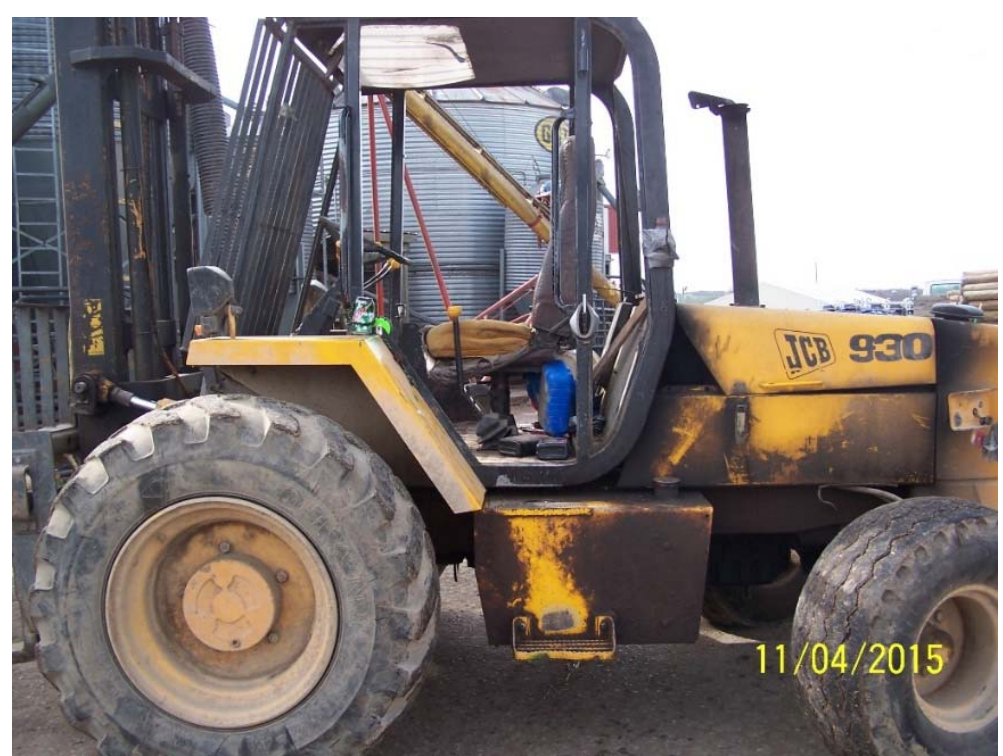

Figure 3. The JCB 930 rough terrain forklift at the scene of the incident.

\section{WEATHER}

November 4, 2015, was an overcast day with temperatures ranging from 53 to 75 degrees Fahrenheit. At the time of the incident the temperature was 75 degrees and humidity was at approximately 64\%. Weather was not considered to be a factor in this fatality.

\section{INVESTIGATION}

On November 4, 2015, the Kentucky Fatality Assessment and Control Evaluation (FACE) Program was notified of a fatality involving a forklift and a teen laborer through a media release. An investigation was conducted.

Tuesday, November 3, 2015, was Election Day and schools were closed for the day. The 17year-old victim had just started a part-time job located across the road from his home and was completing his second day of work. His hours were scheduled after school from 3:30 pm to 5:00 pm Monday through Friday and from 8:00 am to noon on Saturdays. However, with school out for the day, he worked an 8-hour shift, covering work hours for other employees while they left to vote. Some of his tasks were waiting on customers, and filling orders for feed, seeds and medicines. 
The victim shadowed a 19-year-old laborer who had been employed for one month, assisting him with various tasks. At approximately 4:50 pm, the 19-year-old laborer announced that he needed to lock the rough terrain forklift up for the night, and offered the victim a ride back to the storage area. The victim climbed onto the side of the forklift, standing on the side step and holding onto the frame of the forklift as they rode approximately 245 feet to the gated storage area (Figure 4). Moments later, as they approached the storage area, the victim volunteered to open the gate to the storage area. The victim jumped off the moving forklift, caught his foot under the forklift's wheel well, and fell face first to the dirt ground below. Unaware the victim had fallen, the young forklift driver proceeded forward until he sensed something beneath the wheel and stopped. The rear tire had run over the victim's chest, rib, and abdominal area. The forklift driver immediately backed the forklift off of the victim. A nearby customer, who happened to be a physician, heard the forklift driver screaming for help and rushed over to

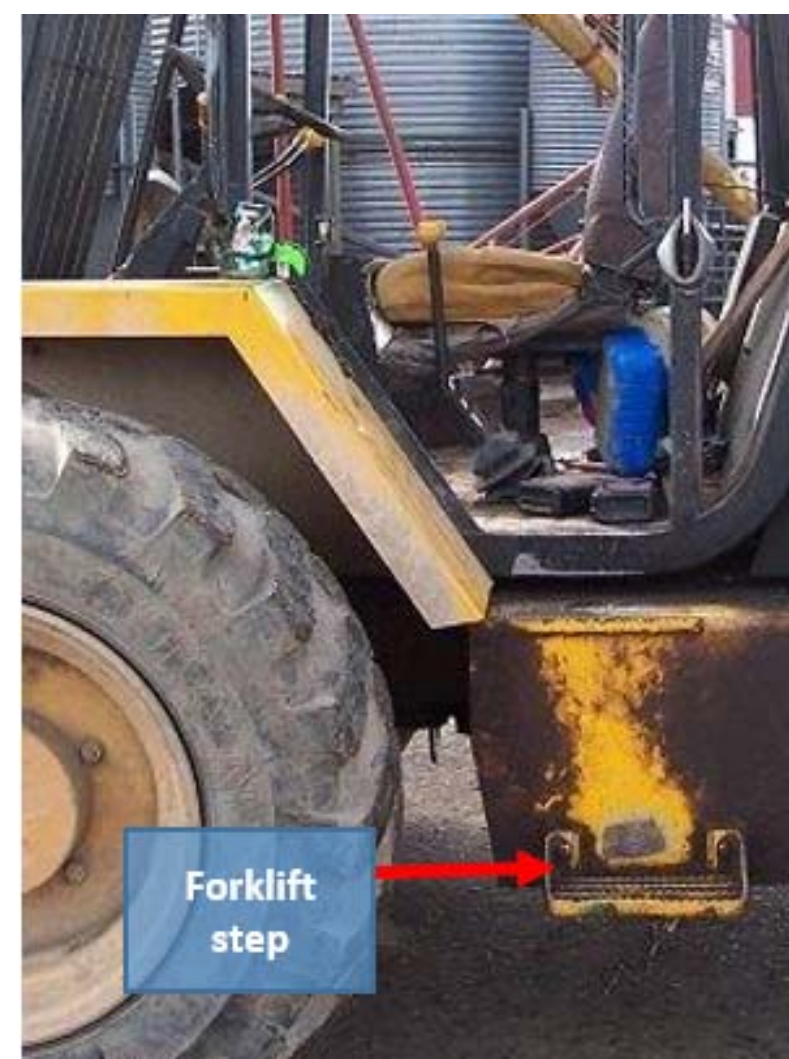

Figure 4. The victim was riding on the forklift's side step at the time of the incident. assist, instructing the employees not to move the victim. After experiencing a seizure, the victim regained consciousness and complained that he was experiencing severe pain. The physician stated the tire had ridden up the side of the victim's abdomen, right shoulder and the side of his head. Emergency medical services were immediately contacted at approximately 5:00 pm and arrived within 15 minutes. After assessing the extent of the victim's injuries, the EMS called for air transport. The victim was flow to a major trauma center where he arrived at 6:15 pm and died at 6:52 pm from his injuries.

\section{CAUSE OF DEATH}

The cause of death was multiple blunt force trauma to the chest and abdomen consistent with being run over by a forklift.

\section{CONTRIBUTING FACTORS}

The investigation identified the following factors that may have contributed to the fatality:

- Insufficiently trained operators

- Passenger riding on equipment designed to accommodate only the driver 
- Lack of knowledge of forklift operation regulations

\section{RECOMMENDATIONS AND DISCUSSIONS}

Recommendation No. 1: Do not allow passenger(s) to ride on a forklift unless the forklift is specifically designed to accommodate passengers.

29 CFR 1910.178(m)(3): “Unauthorized personnel shall not be

permitted to ride on powered industrial trucks (forklifts). A safe place to ride shall be provided where riding of trucks is authorized." 2

OSHA regulations prohibit a passenger from riding on a forklift unless there is a passenger seat available for safe transport. The JCB 930 operator's manual specifically stated that the forklift truck was not designed to accommodate passengers safely.

Recommendation No. 2: Employers should provide and enforce forklift operator safety training. ${ }^{3-4}$

19 CFR $1920.178^{3}$ requires that prior to operating equipment, employees must be provided training on safe operation. The employees must demonstrate they are knowledgeable about the equipment and demonstrate safe operation of the equipment. Training should include operations manual review to understand the limitations and uses of the equipment. The forklift operator was unaware of both the manufacturer's recommendation to not allow passengers to ride on the forklift and of OSHA regulations pertaining to forklift passengers.

Recommendation No. 3: Employers should review regulations pertaining to safe operation of forklifts and other equipment prior to allowing their use on the jobsite.

The employer was unaware that it was an OSHA regulatory violation to ride as a passenger on a forklift that was not designed to accommodate passengers. Employers should educate themselves the safety regulations that govern usage of such equipment. Forklift operation training should be implemented, and compliance strictly enforced.

Please take the time to complete our brief survey regarding this report:

(https://uky.az1.qualtrics.com/SE/?SID=SV_blreE4X2S3FIxHT)

\section{KEYWORDS}

Forklifts

Safety Training

Young Workers

\section{REFERENCES}


${ }^{1}$ Powered Industrial Trucks- Forklifts. United States Department of Labor. OSHA.gov [https://www.osha.gov/SLTC/poweredindustrialtrucks/]

${ }^{2}$ Frequently asked Questions about Powered Industrial Truck Operator Training. United States Department of Labor.OSHA.gov

[https://www.osha.gov/dte/library/pit/pit_q-a.html]

${ }^{3} 29$ CFR 1920. 178(l) OSHA Standards for General Industry. Occupational Safety and Health Administration. 2009. Second edition.

${ }^{4}$ Training Requirements in OSHA Standards. Occupational Safety and Health Administration [https://www.osha.gove/Pulications/osha2254.pdf]

\section{PHOTO CREDIT}

Photos used in this report are the property of the Kentucky FACE program. Photo 2C is credited to Google Maps.

\section{ACKNOWLEDGEMENTS}

The Kentucky FACE program would like to thank the employer for assisting with this report.

\section{PROGRAM FUNDING}

The Kentucky Fatality Assessment \& Control Evaluation Program (FACE) is funded by grant 2U60OH008483-11 from the Centers for Disease Control and Prevention and the National Institute for Occupational Safety and Health.

A brief survey regarding this report can be found here:

(https://uky.az1.qualtrics.com/SE/?SID=SV_blreE4X2S3FIxHT)

Electronic access to this full report can be found here:

(http://www.mc.uky.edu/kiprc/programs/face/files/15KY067.pdf)

\section{FACE on Social Media:}

https://www.facebook.com/Kentucky-FACE-Program$134135740092906 /$ ?view_public for $=134135740092906$

http://www.twitter.com/KYFACEProgram 
This case report was developed by the Kentucky Fatality Assessment and Control Evaluation (FACE) Program. Kentucky FACE is a NIOSH-funded occupational fatality surveillance program with the goal of preventing fatal work injuries by studying the worker, the work environment, and the role of management, engineering, and behavioral changes in preventing future injuries. The FACE Program is located within the Kentucky Injury Prevention and Research Center (KIPRC), part of the University of Kentucky's College of Public Health.

Email: kyfaceprogram@uky.edu | Telephone: 859-257-5839 333 Waller Avenue Suite 242, Lexington, KY 40504 